\title{
PENERAPAN AKUNTANSI LINGKUNGAN UNTUK MENGOPTIMALKAN TANGGUNG JAWAB SOSIAL BAGI PARA PELAKU INDUSTRI
}

\author{
Agung Joni Saputra*, Mia Juliana Siregar* \\ *Universitas Universal \\ Program Studi Akuntansi Fakultas Bisnis \\ Kompleks Maha Vihara Duta Maitreya Bukit Beruntung, Batam \\ E-mail: agungjs13@gmail.com \\ \#Universitas Universal \\ Program Studi Teknik Industri Fakultas Teknik \\ Kompleks Maha Vihara Duta Maitreya Bukit Beruntung, Batam \\ E-mail: mia juliana.1988@yahoo.com
}

\begin{abstract}
Abstrak
Penelitian ini bertujuan untuk menentukan nilai ekonomi wisata dan mengidentifikasi faktor - faktor yang mempengaruhi permintaan pengunjung wisata Pantai Ocarina, Batam. Metode yang digunakan dalam penelitian ini adalah kualitatif (primer) atau dengan menggunakan kuisioner yang disebarkan kepengunjung serta wawancara kepada pengurus pantai setelah mendapatkan data yang dibutuhkan data tersebut diolah dengan menggunakan biaya perjalanan (Travel Cost Method). Metode ini dipilih untuk mengestimasikan potensi ekonomi dipantai Ocarina sebagai salah satu wilayah destinasi wisata. Biaya perjalanan digunakan untuk melakukan perhitungan potensi ekonomi dimana hasil tersebut akan dijadikan standar penentuan nilai Corporate Social Responsibility (CSR). Potensi ekonomi yang dihasilkan oleh pantai Ocarina adalah sebesar Rp 14.959.123.940 dimana potensi ekonomi ini akan dijadikan standar dalam penentuan CSR bagi seluruh pelaku industri di Kota Batam. Jika dilihat dari sisi per individu yang bekerja diperusahaan maka biaya yang ditanggung oleh masing - masing individual yang bekerja adalah sebesar Rp 110.067 - Rp 220.567.
\end{abstract}

Kata Kunci : Akuntansi Lingkungan, Industri, Pariwisata, CSR

\begin{abstract}
The purpose of this study was to determine the economic value of environmental and the factors that influence visitor demand. The method used in this study is qualitative (primary) or uses a questionnaire that spreads Ocarina beach visitors and interviews with beach administrators after obtaining the data needed data using the travel process (Travel Cost Method) this method was chosen to estimate the economic potential of the Ocarina beach as one of the tourist destination areas. Travel costs are used to calculate the economic potential. Where the results will be made the standard determination of the value of Corporate Social Responsibility (CSR). The economic potential generated by Ocarina Beach is Rp. 14,959,123,940 where this economic potential will be used in accordance with CSR standards for all Batam island industries located in Batam Kota, Batu Aji, Bengkong, Sagulung, and Sekupang districts. When viewed from the point of view per person, the costs incurred by each individual are IDR 110,067 - IDR 220,567.
\end{abstract}

Keywords : Environmental Accounting; Industry; Tourism; CSR. 


\section{Pendahuluan}

Industri sangat terikat dengan penggunaan terhadap sumber daya alam (SDA). Tak jarang penggunaan terhadap SDA menimbulkan kerugian bagi alam apalagi jika memiliki lokasi berdekatan dengan Kawasan industri tersebut. Tak jarang hal itu berimbas pada masyarakat sekitar juga.

Masalah lingkungan merupakan permasalahan yang sudah berjalan sejak lama dan banyak peneliti yang mengkaji isu lingkungan ini sesuai dengan perkembangan tekonologi dan ekonomi dunia. Perlahan tapi pasti banyak terjadi perubahan mengenai siklus kehidupan bermasyarakat yang secara langsung memberikan dampak pada lingkungan sekitar. Sekarang banyak isu khususnya pada perkembangan jaman industrialisasi yang sering disebut - sebut yaitu era revolusi industri 4.0 yang mana perusahaan menitik beratkan pada penggunaan teknologi dikarenakan teknologi jauh lebih murah dan lebih mudah perawatannya dibandingkan manusia namun dampak yang terjadi adalah perusahaan menjadi tidak perduli tentang aspek - aspek lingkungan (Arfan, 2008)[1].

Permasalahan mengenai lingkungan saat ini menjadi prioritas bagi pelaku industri dan menyentuh segala aspek termasuk akuntansi menurut (Utama, 2016) [2]. Akuntansi lingkungan sebenarnya bukanlah sesuatu yang baru namun jarang sekali universitas - universitas di Indonesia yang memberikan pelajaran mengenai akuntansi lingkungan.

Akuntansi lingkungan berperan dalam menghitung berapa besar biaya yang harus dikeluarkan oleh pihak industri dalam menyelenggarakan CSR. Dengan semakin maraknya penelitian yang berkaitan dengan topik akuntansi lingkungan, sudah bukan menjadi alasan bagi para pelaku industri untuk tidak menjalankan proses CSR. Banyak negara maju yang melakukan penelitian mengenai akuntansi lingkungan, sedangkan bagi negara berkembang seperti Indonesia sedang dalam proses dijalankan namun bukan berarti Indonesia tidak bisa melaksanakan akuntansi lingkungan. Penelitian yang berasal dari Australia yang dilakukan oleh (Walden \& Stagliano, 1998) [3] mengenai penyediaan informasi mengenai akuntanssi lingkungan lingkungan dalam laporan tahunan negara yang berperan dalam operasi perusahaan.

Irawan (2016) [4] menyebutkan masih banyak perusahaan - perusahaan yang tidak melaksanakan CSR dikarenakan sanksi yang diberikan tidak jelas, hal - hal seperti inilah yang membuat banyak perusahaan - perusahaan memanfaatkan situasi dan lebih menyalahkan ke peraturan yang tidak jelas daripada melakukan CSR dengan sukarela tanpa ada paksaan.

Cakupan akuntansi lingkungan yaitu mengenai mengidentifikasi mengenai biaya dan manfaat merawat lingkungan, dengan disediakannya sarana melalui pengukuran yang bersifat kuantitatif, supaya dapat mendukung alur komunikasi agar mencapai pemeliharaan dan pembangunan jangka panjang, menjaga hubungan yang menguntungkan dengan kelompok serta meraih efektivitas dan efisiensi dari perawatan lingkungan (Ministry of The Environment, Japan, 2005) [5].

Biaya mengenai lingkungan biasanya berhubungan dengan biaya produk, proses, sistem atau fasilitas fasilitas yang dapat digunakan untuk pengambilan keputusan manajemen. Tujuan lainnya dari perolehan biaya adalah bagaimana pelaku industri dapat meminimalisir atau mengurangi biaya-biaya lingkungan, meningkatkan pemasukan serta merawat dan melestarikan lingkungan dengan memberi perhatian pada situasi sekarang, dan masa yang akan datang.

Berdasarkan rangkuman kondisi diatas, masalah yang pasti akan muncul ketika melakukan penerapan akuntansi lingkungan adalah pengukuran (measurement). Menghitung aset yang alami (natural assets) serta menghitung manfaat dan biaya lingkungan yang akhirnya akan dilampirkan kedalam laporan keuangan. (Hansen \& Mowen, 2003) [6] menyebutkan performa lingkungan (environmental performance) memiliki pengaruh yang tinggi dalam posisi keuangan perusahaan khususnya mengenai informasi terhadap biaya lingkungan yang biasanya memiliki kaitan dengan kinerja perusahaan dalam pengelolaan lingkungan hidup.

Makarim di dalam (Utama, 2016) [2] mengemukakan bahwa perusahaan harus memiliki laporan tentang lingkungan hidup dikarenakan laporan tersebut sangat penting dalam menghitung biaya-biaya yang dibutuhkan untuk perawatan lingkungan, perusahaan selain mengeluarkan laporan keuangan setiap tahun. Perusahaan juga harus membuat laporan tentang lingkungan hidup, dengan membuat menyesuaikan dengan kreasinya masing-masing, seperti biaya perawatan lingkungan atau biaya produksi agar tidak mencemari lingkungan.

\section{Kajian Literatur}

Akuntansi lingkungan mempunyai banyak makna dan fungsi. Akuntansi lingkungan dapat menjadi standar dalam akuntansi pendapatan, akuntansi keuangan maupun bisnis internal akuntansi manajerial. Fokus utama dari akuntansi lingkungan 
didasarkan pada alat komunikasi manajerial untuk pengambilan keputusan bisnis internal.

Menurut (Arfan, 2008) [1] akuntansi lingkungan menjadi hal yang patut untuk dipertimbangkan karena akuntansi lingkungan merupakan bagian dari akuntansi atau sub bagian akuntansi. Alasannya mengacu pada keterlibatan dalam konsep ekonomi dan informasi lingkungan.

Pentingnya penggunaaan akuntansi lingkungan bagi pelaku industri atau organisasi lainnya dapat dilihat dalam fungsi dan peran akuntansi lingkungan. Fungsi dan peran akuntansi lingkungan terbagi menjadi dua jenis. Fungsi pertama disebut dengan fungsi internal yaitu internal perusahaan dan fungsi eksternal yang berkaitan dengan stakeholders. Diharapkan dengan adanya publikasi hasil dari akuntansi lingkungan dapat berfungsi dan bermanfaat bagi perusahaan - perusahaan dalam memenuhi pertanggungjawaban dari kegiatan konservasi lingkungan.

Biaya lingkungan pada dasarnya memiliki hubungan terhadap biaya produk, proses, sistem atau fasilitas penting lainnya untuk menjadi dasar dalam pengambilan keputusan manajemen untuk kedepannya. Keuntungan yang diperoleh pelaku industri ketika melakukan konservasi lingkungan berasal dari pencegahan agar kerusakan lingkungan dapat diminimalisir, pengurangan dari perusakan lingkungan, dan atau penggagalan dampak lingkungan, memperbaiki dampak yang dihasilkan, serta melakukan perbaikan setelah terjadi bencana dan kegiatan - kegiatan lainnya yang diukur dalam unit fisik.

Tujuan dari akuntansi lingkungan adalah untuk memberikan informasi mengenai biaya lingkungan bagi para stakeholders. Akuntansi tentang biaya lingkungan telah diatur dalam PSAK 1 tentang Penyajian Laporan Keuangan, PSAK 33 tentang Akuntansi Pertambangan Umum, PSAK 57 tentang Provisi, Kontijen siliabilitas dan Kontijensi Aset di mana adanya transaksi atau kejadian yang erat kaitannya dengan lingkungan hidup, PSAK 25 tentang Kebijakan Akuntansi, Perubahan Estimasi Akuntansi dan koreksi kesalahan, PSAK 64 tentang Eksplorasi Mineral dan PSAK 5 tentang Segmen Operasi. Akuntansi biaya mengidentifikasi,menguantifikasi,mengakumulasi serta melaporkan berbagai elemen biaya yang berkaitan atau memiliki hubungan dengan produksi barang dan jasa.

Menurut UU nomor 40 tahun 2007 tentang perseroan terbatas (UUPT), kewajiban mengenai pemberian CSR tersebut dibatasi pada perseroan atau perusahaan yang kegiatan usahanya berhubungan dengan sumber daya alam (SDA)
(Pemerintah RI, 2007) [7]. Corporate Social Responsibility (CSR) adalah praktek bisnis baru yang mencerminkan gagasan dari perusahaan dalam memenuhi imperatif ekonomi dan konsekuensi sosial dari bisnis (Stojanović, Mihajlović, \& Schulte, 2016) [8]. CSR (tanggung jawab perusahaan, kewarganegaraan perusahaan, bisnis yang bertanggung jawab dan kesempatan sosial perusahaan) adalah sebuah konsep organisasi bisnis menimbangkan kepentingan masyarakat umum dengan mengambil tanggung jawab atas dampak kegiatan yang mereka berikan kepada pelanggan, pemasok, dll masyarakat umum dan pemangku kepentingan lainnya (stakeholders) serta lingkungan mereka (Ismail, 2009) [9].

Tidak hanya pengelola wisata, pemerintah juga mengeluarkan Undang - undang Tanggung Jawab Sosial dan Lingkungan atau CSR, tidak hanya mengatur tentang kegiatan yang dilakukan pelaku industri yang ikut serta dalam pembangunan ekonomi lingkungan setempat, tetapi memiliki kewajiban bagi perusahaan dalam melestarikan lingkungan hidup. Oleh karena salah satu bentuk bidang usaha seperti PT (Perseroan Terbatas) diwajibkan untuk menyiapkan dana CSR untuk membangun ekonomi dan menjaga kelesatarian lingkungan hidup sekitar. Salah satu cara menentukan besaran dana CSR dilakukan dengan metode Travel Cost Method (TCM).

Identifikasi nilai ekonomi sendiri dilakukan dengan menggunakan metode Travel Cost Method, yaitu, Metode biaya perjalanan biasanya digunakan untuk menilai situs yang digunakan untuk rekreasi, meskipun masih dapat digunakan untuk kepentingan lainnya (Salma \& Susilowati, 2004) [10]. Metode ini dapat menetapkan nilai (termasuk surplus konsumen, bukan hanya keinginan untuk membayar) untuk ditempatkan untuk menghapus situs atau pembuatan situs baru. Dalam beberapa aplikasi juga dapat digunakan untuk menilai perubahan dalam kualitas lingkungan di situs rekreasi.

\section{Metode Penelitian}

Objek penelitian ini adalah wisata pantai Theme Park Ocarina dan Kawasan industri di sekitar wisata alam. Penelitian ini menggunakan metode Travel Cost Method untuk menilai tempat rekreasi Ocarina yang nantinya akan dijadikan standar dalam pengambilan biaya CSR yang harus dikeluarkan oleh para pelaku industri.

Cara pengambilan sampel adalah dengan menggunakan data primer atau menyebarkan kuisioner, dimana kuisioner akan disebarkan melalui aplikasi Google form kepada orang-orang yang pernah berkunjung ke pantai Ocarina dan 
beberapa kuisioner disebarkan langsung dilokasi pantai Ocarina.

\section{Hasil dan Pembahasan}

Batam terkenal dengan kota industri. Pada (Gambar 1) Batam pada tahun 2014 memiliki 158 perusahaan berskala besar (large scale) dengan total tenaga kerja sebanyak 114.49 dan sebanyak 140 perusahaan berskala sedang (medium scale) dengan total tenaga kerja sebanyak 6.41, gambar 1 didapatkan dari Badan Pusat Statistik (BPS) Kota Batam [11] dimana data yang kami ambil adalah data yang diupadate oleh BPS per tanggal 8 januari 2019.

Dengan banyaknya jumlah industri dikota Batam, sudah selayaknya para pelaku industri memperhatikan kota Batam yang menjadi tempat pelaku industri menghasilkan keuntungan. Selain kota industri, Batam juga memiliki banyak tempat rekreasi berupa pantai. Hal ini dikarenakan wilayah geografisnya yang dikelilingi oleh lautan. Selain itu Batam merupakan pulau terdekat dengan negara Singapura dan Malaysia, dikarenakan faktor geographis ini lah batam menjadi salah satu wilayah yang sering dikunjungi oleh turis manca negara.

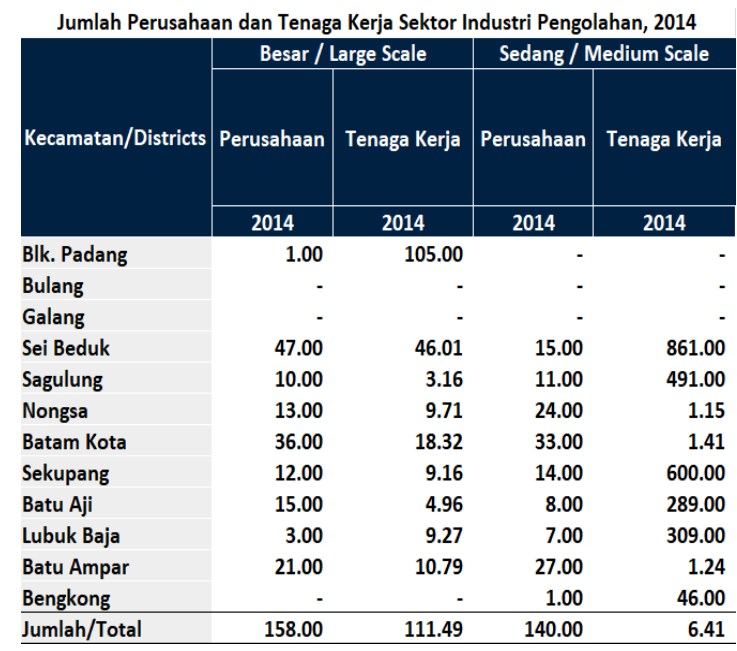

Sumber : (BPS Kota Batam, 2019)

Gambar 1. Jumlah industri di Kota Batam

Karakteristik dari para pengunjung yang menikmati kawasan wisata Pantai Ocarina dari hasil pengisian kuisioner dapat dijelaskan sebagai berikut;

1. Sample yang dianggap mewakili populasi bersifat heterogen. Sample yang dipilih secara acak menunjukkan wanita sebanyak $46 \%$ dan pria $54 \%$ dari total 100 responden. Responden berasal dari Kelurahan Batam Kota sebanyak 74\%, Batu Aji $7 \%$, Bengkong 9\%, Sagulung 2\%, dan Sekupang $8 \%$.

2. Pengunjung terbanyak wisata Ocarina merupakan pegawai swasta dan pelajar. Hal ini menunjukkan fenomena bahwa pegawai swasta dan pelajar lebih sering melakukan aktivitas berlibur ke kawasan wisata sebesar $62 \%$. Frekuensi kunjungan ke wisata Ocarina mendukung informasi kesukaan masyarakat yang lebih memilih pantai sebagai tempat berwisata. Rata - rata pengunjung melakukan kunjungan 2 - 6 kali dalam setahun ke mega wisata Ocarina.

3. Pengunjung lokal cenderung berkunjung ke kawasan Ocarina di sore hari. Hal ini karena kondisi cuaca dan lingkungan Batam yang cukup panas di pagi dan siang hari. Kunjungan yang dilakukan di sore hari menyebabkan masyarakat biasanya hanya menghabiskan waktu paling lama 4 - 6 jam saja. Hal ini menunjukkan banyak orang yang menikmati aktivitas berwisata di pantai. Pihak pengelola mengatakan bahwa lokasi wisata dibuka mulai pukul delapan pagi (08.00) hingga sepuluh malam (22.00) untuk weekday dan pukul enam pagi (06.00) s/d sebelas malam (23.00) untuk weekend.

4. Dalam berwisata biasanya orang akan lebih mengajak teman atau anggota keluarga. Karena pada hakekatnya berwisata adalah saat dimana kita menghabiskan waktu dengan orang - orang yang kita cintai.

5. Menuju lokasi wisata termasuk dalam kategori mudah sebesar 80\%. Hal ini didukung oleh infrastruktur jalan yang sangat memadai di Centre Batam. Hampir diseluruh bagian wilayah Batam Centre sudah memiliki jalan yang diaspal dan tidak ada yang berlubang. Akan tetapi, saat menuju lokasi wisata terdapat sepanjang $2 \mathrm{~km}$ jalan rusak yang dalam proses perbaikan. Para wisatawan lebih memilih menggunakan mobil untuk berwisata, hal ini disebabkan mereka yang mengajak keluarga dan untuk mempermudah perjalanan sebesar $46 \%$, selain mobil transportasi terbesar untuk ke lokasi wisata lebih banyak menggunakan sepeda motor sebesar $43 \%$. Angkutan umum hampir tidak ada yang melalui lokasi wisata Ocarina Theme Park.

6. Untuk menuju ke Kawasan wisata ini, pengunjung juga menghadapi kendala yang tersaji pada diagram dibawah ini, seperti:

- Jalanan menuju Kawasan yang rusak sebesar $52 \%$.

- Pantainya terkadang kotor sebesar $21 \%$.

- Kurangnya fasilitas umum seperti toilet umum dan mushola sebesar $19 \%$.

Selain masalah infrastruktur rusak, pengunjung pantai juga dihadapkan pada kendala fasilitas umum seperti toilet dan mushola yang minim sekali. Dengan jumlah pengunjung dalam 1 hari 
bisa mencapai \pm 290 orang sudah seharusnya didukung dengan toilet umum yang memadai.

Tidak tersedianya informasi berkenaan dengan nilai barang tempat wisata bagi konsumen, bukan berarti mereka tidak memiliki nilai. Oleh karena itu wajar bahwa suatu usaha harus dilakukan untuk memperkirakan nilai dalam beberapa cara.

Identifikasi nilai ekonomi dengan menggunakan metode Travel Cost Method yaitu, metode biaya perjalanan biasanya digunakan untuk menilai tempat rekreasi, meskipun masih dapat digunakan untuk kepentingan lainnya (Salma \& Susilowati, 2004) [10]. Dengan menggunakan rumus perhitungan valuasi ekonomi TCM.

Selain itu, perlu diketahui besarnya Consumer Surplus dan Total benefit dari tempat wisata yang diperkirakan. Surplus konsumen diperoleh dari fungsi permintaan yang digambarkan seperti pada fungsi persamaan dibawah;

$\ln \mathrm{V}_{i j}=\mathrm{b}_{0 j}-b_{1 j} \ln \mathrm{TC}_{i j}+b_{5 j} \ln \mathrm{Y}_{i j}+b_{4 j} \ln \mathrm{S}_{i j}$

Ket :

- $\quad \mathrm{Vi}=$ trip kunjungan dari zona $\mathrm{j}$ per 1000 penduduk

- $\quad$ TCij = biaya perjalanan individu ke-i yang berasal dari zona $\mathrm{j}$

- $\quad$ Yij $=$ pendapatan individu ke-i yang berasal dari zona $\mathrm{j}$

- $\quad \mathrm{Sij}=$ = biaya perjalanan ke lokasi wisata substitusi yang dikeluarkan oleh individu ke$\mathrm{i}$ yang berasal dari zona $\mathrm{j}$

$\mathbf{C S}=-\mathbf{V}_{i j} / \mathbf{b}_{i j}$

$\mathrm{B} \quad=\mathrm{CS}_{j} \boldsymbol{x} \mathrm{TVj}$

Maka diperoleh nilai Customer surplus dan Benefit dari tempat wisata (Tabel1)

Tabel 1. Fungsi Permintaan Kunjungan Wisata

\begin{tabular}{lccc}
\hline \multicolumn{1}{c}{ Lokasi } & Ln & CS & B \\
\hline Batam & & & \\
Ctr & 20,55 & $8.262,858$ & 1.433 .432 .299 \\
Batu Aji & 18,47 & $23.230,661$ & 1.517 .775 .261 \\
Bengkong & 19,18 & $41.889,743$ & 4.449 .528 .482 \\
Sagulung & 17,32 & $108.158,598$ & 9.322 .514 .017 \\
Sekupang & 19,48 & $27.729,184$ & 1.750 .626 .593 \\
\hline
\end{tabular}

Sumber : diolah sendiri

Penentuan jumlah kunjungan per (1000) penduduk (Tabel 2) memerlukan data jumlah penduduk pada masing-masing zona. Data dirubah (transformasi) dengan persentase responden sebagai persentase dari jumlah kunjungan wisata untuk tahun sebelumnya (h-1) dimana hal ini digunakan untuk memprediksikan jumlah pengunjung zona. Setelah itu dicari jumlah pengunjung per 1000 penduduk dengan membagi jumlah pengunjung setiap zona dengan jumlah per 1000 penduduk.

Tabel 2. Jumlah pengunjung per 1000 Penduduk

\begin{tabular}{lccc}
\hline $\begin{array}{c}\text { Daerah } \\
\text { (Zona) }\end{array}$ & $\begin{array}{c}\text { Jumlah } \\
\text { penduduk }\end{array}$ & $\begin{array}{c}\text { Prediksi } \\
\text { pengunjung } \\
\text { (orang) }\end{array}$ & $\begin{array}{c}\text { Kunjungan } \\
/ 1000 \\
\text { penduduk } \\
\text { (orang/tahun) }\end{array}$ \\
\hline Batam & 173.479 & 78.544 & 453 \\
Ctr & 65.335 & 7.430 & 114 \\
Batu Aji & 106.220 & 9.553 & 90 \\
Bengkong & 86.193 & 2.123 & 25 \\
Sagulung & 63.133 & 8.491 & 134 \\
Sekupang & & 106.140 & \\
Jumlah & & & \\
\hline
\end{tabular}

Sumber : diolah sendiri

Dari tabel 2 diatas dapat diketahui jumlah pengunjung yang berkunjung ke pantai Ocarina. Dengan mengikuti data diatas maka didapatkan jumlah prediksi pengunjung per 1000 penduduk, setelah mendapatkan data pengunjung per 1000 penduduk maka dilanjutkan ke penentuan nilai ekonomi (valuasi) wisata didasarkan pada pendekatan biaya perjalanan (travel cost), yaitu jumlah uang dihabiskan untuk melakukan perjalanan Biaya tersebut meliputi transportasi, konsumsi, wahana bermain, dan lainnya termasuk karcis, toilet yang dimasukan sebagai Opportunity Cost yang bisa dilihat pada Tabel 3.

Tabel 3. Biaya perjalanan per zonasi

\begin{tabular}{lrrr}
\hline $\begin{array}{l}\text { Daerah } \\
\text { (Zona) }\end{array}$ & $\begin{array}{c}\text { Biaya } \\
\text { Perjalanan }\end{array}$ & $\begin{array}{l}\text { Opportunity } \\
\text { cost waktu } \\
\text { perjalanan }\end{array}$ & $\begin{array}{l}\text { Total biaya } \\
\text { perjalanan }\end{array}$ \\
\hline Batam Ctr & 10.053 .580 .800 & 273.593 .540 & 10.327 .174 .340 \\
Batu Aji & 1.426 .521 .600 & 94.110 .800 & 1.520 .632 .400 \\
Bengkong & 1.003 .023 .000 & 48.399 .840 & 1.051 .422 .840 \\
Sagulung & 437.296 .800 & 30.922 .120 & 468.218 .920 \\
Sekupang & 1.502 .942 .400 & 88.733 .040 & 1.591 .675 .440 \\
Jumlah & 14.423 .364 .600 & 535.759 .340 & $\mathbf{1 4 . 9 5 9 . 1 2 3 . 9 4 0}$ \\
\hline
\end{tabular}

Sumber : diolah sendiri

Kegiatan wisata yang dilakukan oleh pengunjung dengan domisili yang sangat jauh akan mengeluarkan total biaya perjalanan yang paling besar.

Nilai valuasi (Tabel 3) dari Theme Park Ocarina adalah sebesar Rp14.959.123.940. Potensi nilai sebesar itu memberikan dampak yang positif bagi pembangunan penduduk lokal. Nilai CSR yang perlu dikeluarkan perusahaan - perusahaan per individu per zonasi.

Selain biaya perjalanan, biaya opportunity cost akibat biaya perjalanan juga menjadi pertimbangan untuk menentukan nilai ekonomi. Opportunity cost 
ditentukan berdasarkan konversi UMR (Upah Minumum Rata-rata) yang berlaku pada tahun penelitian yaitu Rp. 3.800.00.-/bulan. Diasumsikan jam kerja 8 jam/ hari, 25 hari kerja dalam satu bulan, sehingga konversi tingkat upah minimum dalam menit adalah Rp 316,667/menit (Tabel 4).

Biaya CSR bila ditransformasikan menjadi biaya per individu (Tabel 4) adalah dari jarak paling dekat (Bengkong) Rp110.067/orang hingga paling jauh sebesar Rp220.567/orang (Sagulung).

Hasil regresi antara jumlah kunjungan per seribu (1000) penduduk dengan variabel-variabel bebas (X1, X2, X3) menghasilkan model permintaan sebagai berikut: $\operatorname{Ln} \mathrm{Y}=-122,52+4,59 \operatorname{LnX} 1+$ 8,42 LnX2 - 4,83 LnX3.

Tabel 4. Biaya perjalanan individu per zonasi

\begin{tabular}{cccc}
\hline $\begin{array}{c}\text { Daerah } \\
\text { (Zona) }\end{array}$ & $\begin{array}{c}\text { Prediksi } \\
\text { pengunjung } \\
\text { dari zona } \\
\text { (orang) }\end{array}$ & $\begin{array}{c}\text { Total } \\
\text { perjalanan per } \\
\text { zona }\end{array}$ & $\begin{array}{c}\text { Total biaya } \\
\text { perjalanan } \\
\text { per individu } \\
\text { per zona }\end{array}$ \\
\hline Batam Ctr & 78.544 & 10.327 .174 .340 & 131.483 \\
Batu Aji & 7.430 & 1.520 .632 .400 & 204.667 \\
Bengkong & 9.553 & 1.051 .422 .840 & 110.067 \\
Sagulung & 2.123 & 468.218 .920 & 220.567 \\
Sekupang & 8.491 & 1.591 .675 .440 & 187.450 \\
\hline Sumber : Diolah sendiri & &
\end{tabular}

Sumber : Diolah sendiri

Model tersebut sangat nyata $(\mathrm{P}=0,05)$ dengan koefisien determinasi sebesar 84,3\%. Tanggung jawab sosial yang perlu dijalankan oleh pelaku industri dalam rangka mematuhi aturan UU 40 tahun 2007 tentang dana CSR terhadap kawasan wisata dengan nilai ekonomi yang telah dtentukan diatas antara lain:

1. Penghijauan bagi lingkungan sekitar, seperti menanam pohon bakau sehingga mengurangi erupsi pantai.

2. Membuat fasilitas umum seperti tempat sampah, toilet dan perbaikan infrastruktur akses menuju lokasi pantai wisata.

3. Mengadakan program kebersihan pantai dengan melibatkan masyarakat sekitar dan pengunjung pantai melalui rangkaian acara bakti sosial.

4. Menjaga keberlangsungan fungsi lingkungan hidup di sekitar pantai.

5. Melakukan penyuluhan/membuat iklan-iklan diarea lokasi tempat wisata agar tidak membuang sampah sembarangan.

\section{Kesimpulan}

Adapun kesimpulan penelitian in yaitu:

1. Theme Park Ocarina memiliki nilai benefit berdasarkan sudut pandang masing - masing zonasi. Nilai benefit Ekonomi wisata Ocarina memiliki nilai paling tinggi jika dipandang dari zonasi Batam Center hal ini dikarenakan Batam Center memiliki tingkat penduduk yang tinggi yaitu sebesar 173.479.

2. Penentuan nilai ekonomi (valuasi) wisata didasarkan pada pendekatan biaya perjalanan (travel cost), yaitu jumlah uang yang dikeluarkan untuk melakukan perjalanan wisata ke Theme Park Ocarina. Dari hasil perhitungan, nilai valuasi dengan pendekatan biaya perjalanan bernilai paling besar pada zonasi yang memiliki jumlah penduduk paling besar, yaitu pada wilayah Batam Centre.

3. Berdasarkan nilai valuasi ekonomi wisata Theme Park Ocarina, dapat ditentukan besaran biaya CSR yang wajib ditanggung oleh seluruh pelaku industri di Kota Batam untuk kecamatan Batam Kota, Batu Aji, Bengkong, Sagulung, dan Sekupang. adalah sebesar Rp 14.959.123.940. Jika biaya CSR ini dilihat dari biaya per individu, maka diperoleh biaya CSR mulai dari Rp 110.067 - Rp 220.567 per individu, yang berarti bahwa setiap individu yang bekerja disuatu perusahaan. Perusahaan tersebut memiliki kewajiban untuk mengeluarkan dana CSR sebesar kurang lebih Rp 110.067 - Rp 220.567.

4. Hasil regresi antara jumlah kunjungan per 1000 penduduk dengan variabel-variabel bebas $(\mathrm{X} 1, \mathrm{X} 2$, $\mathrm{X} 3)$ tersebut sangat nyata $(\mathrm{P}=0,05)$ dengan koefisien determinasi sebesar $84,3 \%$.

\section{Ucapan Terima Kasih}

Terima kasih ditujukan bagi pihak pemerintah khususnya Kemenristekdikti yang memberikan dana hibah Penelitian Dosen Pemula (PDP) kepada kami untuk melakukan penelitian ini, serta kepada pengelola Theme Park Ocarina, khususnya petugas penjaga pintu utama yang telah berbagi informasi bagi penelitian ini, dan kepada para responden yang bersedia mengisi kuisioner penelitian ini.

\section{References}

[1] Arfan, I. (2008). Akuntansi Lingkungan dan Pengungkapannya. Yogyakarta: Graha Ilmu.

[2] Utama, A. (2016). Akuntansi Lingkungan sebagai Suatu Sistem Informasi. Jurnal Bisnis dan Manajemen, 89-100.

[3] Walden, W., \& Stagliano, A. (1998). Assesing the Quality of Environmental Disclosure Themes. The Second Asian Pasific Interdisicplinary Research in Acccounting Conference.

[4] Irawan. (2016, May 26). Batam Today. Retrieved from Batamtoday.com: 
http://m.batamtoday.com/berita72398-BanyakPerusahaan-Tak-Laksanakan-CSR,-karena-

Sanksinya-Tak-Diatur-Secara-Jelas.html

[5] Ministry of The Environment, Japan. (2005). Environmental Accounting Guidlines. Japan. Tokyo: Ministry of The Environment, Japan.

[6] Hansen, \& Mowen. (2003). Management Accounting. Ed 6th. New Jersey: Southwestern.

[7] Pemerintah RI. (2007). Undang - Undang No 40 tentang Perseroan Terbatas. Indonesia.

[8] Stojanović, A., Mihajlović, I., \& Schulte, P. (2016). Corporate Social Responsibility: Environmental Aspects. International May Conference On Strategic ManagementImksm2016. Bor, Serbia .

[9] Ismail, M. (2009). Corporate Social Responsibility And Its Role In Community Development: An International Perspective . The Journal Of International Social Research, 199-210.

[10] Salma, I., \& Susilowati, I. (2004). Analisis Permintaan Objek Wisata Alam Curug Sewu, Kabupaten Kendal Dengan Pendekatan Travel Cost. Dinamika Pembangunan, 153 - 165.

[11]Bps Kota Batam. (2019, January 08). Badan Pusat Statistik Kota Batam. Retrieved From Badan Pusat Statistik Kota Batam: Https://Batamkota.Bps.Go.Id/Statictable/2015/ 12/17/35/Jumlah-Perusahaan-Dan-TenagaKerja-Sektor-Industri-Pengolahan-20132014.Html 